\title{
A Brief Discussion on the Promotion Role of "Double World-classes" Development to Education For International students in China
}

\author{
Xin Zhao \\ Alumni House, Fuzhou University, Xueyuan Road 2\#, Minhou, Fuzhou, Fujian, P. R. China \\ faoz@fzu.edu.cn
}

Keywords: "Double World-classes", the education for international students in China

\begin{abstract}
At present, "Double World-classes" Development is one of the hottest topics of higher education in China. Although it is not involved in the total plan of the "Double World-classes" Development, the education for international students in China, as an important part of the internationalization of China's higher education, shall also be given attention to. Now, the education has won a success in quantity, and in the future it should pay attention to enhancing the ability to serve the national strategy, improving quality and efficiency, and building China's own international education brand.

According to the statistical data of the Ministry of Education of China, there were more than 440 thousand foreigners studying in China in 2016; and there were more than 10 thousand international students studying in over 10 provinces and cities such as Beijing City, Shanghai City, Jiangsu Province and Zhejiang Province respectively. After over 10 years of rapid development, the goal of "Study in China Plan" proposed by the Ministry of Education of China in 2010 has been achieved in advance. For example, China has become Asia's largest destination country for international students, and judging from the view of "quantity", the set objective of attracting 500 thousand international students in 2020 will soon be achieved, which is such an exciting achievement. So in the face of the vigorous development of internationalization of higher education, what is the development direction in the future of the education for international students in China? The “Double World-classes” Development precisely points out the new way.
\end{abstract}

\section{The development of education for international students in China is the inevitable choice in the "Double World-classes" Process}

The "Double World- classes" Development means: by 2020, a number of universities and disciplines in China will enter the list of world-class universities, and a number of disciplines will enter the forefront of world-class disciplines; by 2030, more universities and disciplines will enter into the world-class list, a number of universities into the forefront of world-class universities, a group of disciplines into the forefront of world-class disciplines, and the overall strength of higher education will be significantly improved; by the middle of this century, the quantity and strength of first-class universities and disciplines will remain its leading position in the world, and a powerful country of higher education will be basically built up. It is well known that the "Double World-classes" Development is another major higher education promotion project of the Chinese government following the "985", "211" and other state-level educational projects, aimed at comprehensively enhancing the overall strength of China's higher education in talent training, scientific research, social service and culture inheritance and innovation and international exchanges and cooperation. Universities in China all give great attention and put a lot of high-quality education resources in the Development, wishing to enter the list of the "Double World-classes" Development and enhance their ability to run the school and their international influence. Up to this day, it has been widely believed that the education for international students in China is an important part of the internationalization of higher education, so the function of the "Double World-classes" Development to promote the education for international students in China is self-evident. 
From the international practice perspective, increasing investment and development in education for international students is also a common choice of world-class universities and one of the basic characteristics of first-class universities. University is an academic institution of producing thoughts, and the collision of ideas and the exchange of spirit need education to maintain an open mind. When people from different cultures, different beliefs, and different knowledge backgrounds come together for knowledge, the academic environment created by them is extremely valuable to human creativity. In the context of further developing the internationalization of higher education, the competition for high-quality students around the world has become a common phenomenon in the development of higher education in today's world. Massachusetts Institute of Technology enrolls 1438 undergraduate freshmen in 2017 from 1000 high schools from 50 states of the USA and 62 countries and regions across the globe, which can reflect its degree of internationalization. The international students coming from more than 100 countries account for about $40 \%$ of more than 20,000 students of Oxford University in the UK, and international students take up 60\% of its full-time postgraduates. The internationalization of student sources provides Oxford University with an international campus culture, and the convergence of students from different nations, societies, education backgrounds and ethnics contributes to the achievement of international education of Oxford University. Although Nanyang Polytechnic in Singapore does not have a long history, it enjoys a high international reputation in the field of science and engineering, which shall largely attribute to its attention to the cultivation of international students. The proportion of international postgraduates in the school is $53 \%$, while the proportion of the international doctoral students is as high as $76 \%$. Thus we can see that internationalization and globalization are the development trend of first-class universities in the future.

Internationalization is not only explicit, but also endogenous. It is not used to label universities, but to better fulfill missions and achieve functions of universities. The selection criteria of "Double World-classes" specifically refers to the ability of international exchange and cooperation, and it requires that first-class universities shall enhance the attraction to overseas students, have in-depth academic exchanges with world's high-level universities and academic institutions, be able to participate in the development of international standards and rules, and enjoy strong international influence. About 1/3 of Ph.D. degrees of science and engineering in the United States are granted to foreign citizens. No matter whether they return to their own countries or stay in the United States they are a great fortune of these countries. By referring to the selection method of "Double World-classes" Development, education for international students in China is an excellent entry point and can provide sustained and healthy support for other indicators. And then take the University of Chicago as another example. Enthusiastically accepting the outstanding scholars and students around the world and meeting the needs of students as much as possible are the core values and tradition of the education in the University. In early years, because the University recruited a large number of postgraduates each year, many of China's scholars who wanted to study in the United States regarded the University of Chicago as their first choice after graduating from undergraduate schools, and most of them made tremendous contributions to the development of China's science and education courses after returning home. China has become a great power with great influence and is playing an increasingly significant role in the international arena, so the international environment and condition of universities have been significantly improved. Under the initiatives of "Going Global" and the "Belt and Road", universities shall undertake duty-bound historic missions, and it is imperative to draw on and learn from the experience of talent training and university governance from world-class universities, attract overseas high-quality students, and build the cultivation system for international students in line with the current national needs of China.

\section{The current focus of the education for international students in China}

With the spread of the thought of international school-running and the promotion of the world 


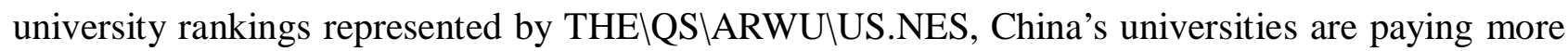
and more attention to the number of international students, investing a lot of resources to improve the proportion of these students. During the 60 years between 1949 and 2009, China totally received about 1.69 million international students, and only during the 4 years from 2010 to 2013, totally 1.2425 million international students were recruited, which was equivalent to $73.4 \%$ of the total number of previous 60 years. The proportion of international students in China to the number in the world is also increasing year by year. At present, the proportion is about 6-7\%, which is not high compared with the United States (22\%) and the United Kingdom (14\%). But with enhancement of comprehensive national strength and the reinforcement of international influence, there will be more international students choosing China as their foreign study destination.

China has become a major country for international students, but not a strong one. In general, the measurement indicator of the quality of international students in a university is not only the quantity, but also the proportion of international students to all students and the proportion of students owning a diploma. However the education for international students in China does not have the upper hand in both. Some scholars argue that one of the criteria to evaluate the internationalization level of higher education is that "the percentage of international students to total students shall not be less than 20\%." Compared with world-class universities, the proportion of international students in China's universities is still relatively low. In 2017, Academic Ranking of World Universities (http://www.zuihaodaxue.cn/) made rankings based on the proportion of international students owning a diploma to total students in China's universities (including undergraduates, postgraduates, and doctoral students). In addition to NYU Shanghai with the Sino-foreign cooperation in running schools, Beijing Language and Culture University ranks first only with the proportion of $25 \%$, and the percentage of other domestic colleges and universities is even lower. From the perspective of the proportion of students with diplomas, the proportion of international students in countries powerful in international student education is usually over $50 \%$.According to the statistics of the Ministry of Education, in 2016 there totally were 209 thousand international students receiving academic education in China, accounting for $47.42 \%$ of the total international students in China, and conditions are different in different schools, which means the academic students still have great potential for development. In general, the education for international students in China is still in the stage of self-crossing and catching up, and its education level still need to be improved. The "Study in China Plan" of the Ministry of Education proposes to build an international brand for China's education, whose realization depends not only on the quantity of international students, but also on the quality and the reputation of our education. Based on this, the current education output in China shall use the external strategy to promote the internal condition and enhance the degree of internationalization and influence of higher education; cultivate the international brand of China's education and train high-level international talents; play the role of bridge of international students, promote international exchanges and cooperation, and build a good international environment.

\section{Demands raised by the "Double World-classes" Development to the education course for international students in China}

In the history of the development of higher education in the world, compared with the United Kingdom, France and Germany, the United States is a late starter. But to this day, the United States has become the world's center of higher education and science and technology culture. Among many world-class university rankings, the number of American universities is far ahead, occupying most of the top seats. Late-Starting Advantage Theory considers that, "because of backwardness, many aspects of their development process will be different from the advanced countries." It is exactly the case for China with post-modernization of higher education. The successful experience of the United States is worth our reference, and the education for international students in China shall combine with the "Double World-classes" Development to get a promotion in quality. 


\subsection{Improve the status of the education for international students in China to actively serve the national development strategy}

Ministry of Education of China has incorporated the education for international students in China into the overall plan such as the "Double World-classes" Development and internationalization strategy of education in China's universities. It has become the consensus in China's education sector that the education for international students shall become an important force to support the national strategy. We shall strive to develop the education to cultivate a large number of high-quality people knowing China and being friendly to China and to create a good international diplomatic environment for realizing the national development strategy. At present,the internationalization of China's higher education shall follow the direction of the structure adjustment of international students in China and the improvement of the education quality, and shall no longer be solely limited to the expansion in quantity.

\subsection{Improve quality and efficiency to concentrate high-quality resources to build our education brand}

The high-quality education for international students has two basic characteristics, one is to obtain students around the world with first-class quality, the other is to own the ability to cultivate world leaders in all walks of life, and the possession with advanced education concept is the basic premise to improve the quality of the education for international students. Combined with the "Double World-classes" Development, the education for international students in China should pay attention to cultivating high-level students such as postgraduates and doctoral students and supporting the growth of high-end talents. Generally speaking, the scale of high-level international students marks the internationalization level of higher education of a country, and, especially, doctoral students can play a more important role in economic construction and social development in a country, which can easily form a good reputation. But not every discipline in world-class universities is in an international leading position, and for most of China's universities, it is impossible to bear fruits in all disciplines. In light of the huge differences in different regions, different subject fields and different school positioning, we shall adhere to the strategy of "do something and giving up something", take a characteristic and differentiated path, and concentrate high-quality resources to train a number of high-quality international students with professional features, forming the scale effect and enhancing the international influence.

\subsection{Build an international students training and education system that is more in line with international practices}

The attraction of a country's higher education to international students depends on, to a great extent, the type, size, quantity and quality of the courses that can be offered by the country. This is the only way that China's education can be recognized by the world. First of all, China's universities should attach importance to introducing international standards to ensure the effectiveness, advancement and internationalism of teaching contents. Second, construct an international faculty. Finally, take a flexible and diverse teaching and assessment methods. Because the educational system of each country and the teaching contents are not the same, the cultivation for international students should meet their teaching characteristics, and on the basis of strengthening the professional Chinese, we shall give international students more opportunities to practice. In addition, professional international certification is also very important, which is the basisfor deep cooperation with world's other first-class universities. In 2013, China joined the world's most influential mutual recognition agreement of international undergraduate engineering degree- "Washington Accord" and offered the "pass" with international mutual recognition quality standards for Chinese engineering graduates to go global in the future, directly promoting the construction of engineering education certification system that is virtually equivalent to the international practice.

\subsection{Increase the scholarship investment to attract overseas high-quality students}

American universities are able to attract high-quality students from all over the world, not only 
because they have a large number of top universities with global reputation, but also because they can provide students with good learning and living conditions, in which the scholarship with wide coverage and high amount is one of the important attractive conditions. To this end, in order to improve the quality of education for international students in China, China also needs to increase the investment to expand the coverage and increase the amount of scholarships for international students to improve the attractiveness to international high-quality students. According to the planning of the Ministry of Education, the design and distribution of scholarships for international students in China will precisely focus on the national strategy. On the one hand, fully lean to the provinces alone the "Belt and Road", on the other hand, support the cultivation of high-end personnel, focusing on the training of world's top talents, such as the Excellence Award Project of the Chinese Government and the Global Youth Leaders' Short Visit Program. Universities can also set up targeted high-level personnel training scholarship based on their own characteristics.

\subsection{Improve the service system for international students and promote service ability}

Whether it is equipped with advanced service system for international students is also an important criterion for judging whether a country or region has international competitiveness and a realistic basis for ensuring the smooth implementation of the education for international students. It will play an important role for international students to merge into the local society, adapt to the local culture and life, and improve their language ability. The education for international students is a systematic project, including international enrollment publicity, educational administration, learning (course selection, academic guidance, etc.), life, graduation and employment guidance, tracking and contact with alumni/alumnae and many other works. Study in China is not a "one-time deal", and no department can realize it by itself. It shall embody school's management philosophy and level in all aspects through the management of whole process and the construction of service system to constantly improve the reputation and attractiveness of the education for international students in China.

\section{Conclusion}

In 19th century, Germany was the power of higher education at that time, and the United States was the main exporter of international students. According to statistics, from 1815 to 1915, there were more than 10,000 young Americans studying in Germany. When they returned to their country, most of them became the backbones of American higher education. They brought back advanced educational ideas and teaching methods, narrowing the gap between the United States and the developed countries of world's higher education. Facts have proved that only a strong country of international study can attract high-quality overseas students. Neither the first-class universities nor the first-class disciplines should forget the original purpose. Instead they should put the cultivation of first-class talents as their responsibility, and, no doubt, international students training is also a part of it.

The current "Double World-classes" Development proposed by China presents a more clear direction for the education for international students in China: through the development of education for international students in China, China can largely strengthen the international elements including the education for international students, promote the internationalization of students, courses, teaching activities, and education and teaching systems, and enhance the educational strength and improve the internationalization level of school running by conducting multi-level, multi-form, and all-round international education.

\section{References}

[1] Bie Dunrong. The Education Concept of World-class Universities [M]. Xiamen: Xiamen University Press, 2016. 
[2] Wang Jun. The Basic Positioning and Coping Strategies of the Education for International students in China [J]. China Higher Education, 2014, 8: 88-92.

[3] Liang Chuanjie. The "Double World-classes" Development of Colleges and Universities: Concept and Action [J]. Journal of National Academy of Education Administration, 2017, 3: 22-28.

[4] Xu Tao. Collaborative Innovation and the Improvement of Quality and Efficiency - The Summary of the Concluding Speech of Comrade Xu Tao in the 2016 National Conference on the Administration Works of the Education for International students in China [J]. Journal of World Education, 2016,24: 47-48.

[5] Song Yonghua. Improve the Quality of Education for International Students in China to Support the "Double World-classes" Development [N]. China Education News, 2017: 5

[6] Parts of the data come from the website of the Ministry of Education: http://www.moe.gov.cn 